\title{
Seasonal variation in fatty acid composition in various parts of broccoli cultivars
}

\author{
Shiva Ram Bhandari, Mi Young Park, Won Byoung Chae, Dae-Young Kim, Jung-Ho Kwak* \\ Vegetable Research Division, National Institute of Horticultural and Herbal Science, Rural Development Administration, Suwon, 440-706, \\ Republic of Korea
}

Received on 11 November 2013, revised on 26 November 2013, accepted on 27 November 2013

\begin{abstract}
To evaluate seasonal variation in fatty acid composition in broccoli, 12 commercial cultivars of broccoli were grown in spring and fall season at the field of NIHHS, and their floret, leaf and stem parts were used for the fatty acid composition analyses. Among 14 fatty acids detected in broccoli, linolenic, palmitic and linoleic acids were major fatty acids comprising more than $80 \%$ of total fatty acids in both the seasons and all the parts. Likewise, stearic and oleic acids were also present in considerable amount while remaining fatty acids; caproic, lauric, myristic, pentadecanoic, palmitoleic, heptadecanoic, arachidic, behenic and lignoceric acids showed their minor compositional ratio. Among the three parts, stem exhibited highest SFAs (49.681\% in spring and 50.717\% in fall season) compared to MUFA and PUFA, while highest compositional ratio of PUFAs were observed in leaves (62.588\% in spring and $68.931 \%$ in fall season), which indicates leaves as a good source of health beneficial fatty acids. In contrast, floret part exhibited highest SFA $(48.786 \%)$ and PUFA (57.518\%) in spring and fall seasons, respectively. Major fatty acids; palmitic, linoleic and linolenic acid showed lowest cultivar dependent variation (below 10\%) and leaf showed least variation in both the seasons compared to floret and stem. Our results suggest that all the fatty acids are significantly influenced by genotype of cultivars (C), plant parts (P) and growing seasons (S). Among the 14 fatty acids, myristic and palmitic acid showed highest positive or negative correlationship with oleic $\left(\mathrm{r}=0.912^{* *}\right)$ and linolenic acid $\left(\mathrm{r}=-0.933^{* *}\right)$, respectively. The most abundant fatty acid, linolenic acid, showed either negative or no correlation ship with other fatty acids while palmitic acid, a second major fatty acid, exhibited either positive or negative correlation ship.
\end{abstract}

Key words : Broccoli, Floret, Stem, Leaves, Seasonal variation, Fatty acids

\section{Introduction}

Fatty acids are important constituents of plants, which provide various human health benefits. The main constituent of all the oil is the fatty acids which include saturated fatty acid (SFA), monounsaturated fatty acid (MUFA) and polyunsaturated fatty acid (PUFA) that influence human physiology in different ways. These fatty acids are classified as essential fatty acids; linolenic and linoleic fatty acid and non essential fatty acids depending upon the body requirement and synthesis. Essential fatty acids are required for the human body since they cannot be synthesized and

\footnotetext{
*Comesponding author: Tel: +82-31-240-3642

E-mail address: jhknest@korea.kr
}

must be acquired through diet. As the saturated fatty acids increase the risks of cardiovascular diseases, cancer and autoimmune disorders (Iso et al., 2002), high ratio of such fatty acids in foods are not suitable for human health. In contrast, a diet rich in unsaturated fatty acids are more nutritional (Aronson et al., 2001) because a diet rich in mono unsaturated fatty acids such as oleic acid, may decrease blood cholesterol levels (Hargrove et al., 2001), improve high-density lipoprotein (HDL) fluidity (Villa et al., 2002) and protects against ischemic and stroke and lacunar infarction (Iso et al., 2002). Similarly, polyunsaturated fatty acids, such as linoleic and linolenic acids, may benefit the structure and function of membrane proteins, enzymes, and active transport molecules (Yaqoob, 2002), and their different compositional ratio is related to 
the reduction in many cardiovascular diseases, cancer, asthma as well as depression (Simopoulos, 2002). So the compositional ratio of these fatty acids in any food products is an important factor that determines the nutritional value of the food.

Broccoli, a member of genus Brassica is one of the most commonly consumed green vegetable throughout the world. It contains a wide range of health beneficial phytochemicals and a good source of glucosinolates, vitamins, phenols and flavonoids. Previous studies in broccoli showed the presence of considerable amount of wide range of various health beneficial phytochemicals such as glucosinolates, vitamins, carotenoids, minerals, phenolics and flavonoids (Rosa and Rodrigens, 2001; Podsedek, 2007; Singh et al., 2007; Koh et al., 2009). There are several reports having fatty acid composition in seeds as well as vegetative parts of several Brassica crops (Velasco et al., 1998; West et al., 2002; Matthaus et al., 2003; Barthet, 2008; Vidrih et al., 2009), however information regarding fatty acid composition in broccoli is limited. Although, fatty acid composition in floret part of broccoli has been studied (West et al., 2002; Vidrih et al., 2009), only one cultivar was selected and the name was not clearly identified. Furthermore, regarding the fatty acid composition in leaves and stem parts, there are no official data available. So it will be noteworthy to find out the compositional ratio of fatty acids in different parts of various commercial broccolis. Therefore, with this study, we aimed to analyze various saturated as well as unsaturated fatty acids in commercial broccoli cultivars, to determine how these fatty acids are distributed in their different parts, to trace the influence of growing seasons in their compositional ratio and to find how these fatty acids are correlated to each other.

\section{Materials and Methods}

\section{Plant Materials}

Twelve commercial broccoli cultivars namely 05-C3,
AMaGi, BaeRiDom, CheonJae, Diamond, Grace, Grandeur, JikNok\#28, NokJae, NokYeom\#1, TS-2319 and YuDoRi\#1 were grown at the experimental filed of NIHHS, RDA (Suwon, Korea) in spring and fall seasons. After harvesting at 80 days after sowing, the plants were then separated into floret, leaf and stem parts. They were freeze dried and ground into fine powder and then stored at $-20^{\circ} \mathrm{C}$ until the use for chemical analyses.

\section{Sample preparation of fatty acid composition}

Samples for fatty acid composition analysis were prepared according to Bhandari et al. (2012). Powdered broccoli samples $(0.1 \mathrm{~g})$ were mixed with $680 \mu \mathrm{L}$ of methylation mixture (MeOH: benzene: 2,2-dimethoxypropane: $\mathrm{H}_{2} \mathrm{SO}_{4}=39: 20: 5: 2$ by volume) and $400 \mu \mathrm{L}$ of heptane. After vigorous mixing, the solution was heated for $2 \mathrm{~h}$ at $80^{\circ} \mathrm{C}$ in a water bath and cooled to room temperature. Then the heptanes layer was collected by centrifugation and was injected into the GC for fatty acid composition analysis.

\section{Fatty acid composition analysis}

Fatty acid composition was analyzed using a GC (CP-3800; Varian, Mulgrave, VIC, Australia) equipped with a flame ionization detector and a capillary column: CP SIL 88 CB FAME (50 m $\times 0.25$ mm, $0.25 \mu \mathrm{m})$ according to method described by Bhandari et al. (2012). The temperature was set $210^{\circ} \mathrm{C}$ for both the injector and FID detector. The injection volume was $1 \mu \mathrm{L}$ with split ratio $1: 50$ on constant column flow (1 $\mathrm{mL} / \mathrm{min}$ ) of helium gas. The oven temperature was initially maintained at $100^{\circ} \mathrm{C}$ for $5 \mathrm{~min}$, and FID increased up to $160^{\circ} \mathrm{C}$ at a rate of $5^{\circ} \mathrm{C} / \mathrm{min}$, maintained for $5 \mathrm{~min}$, and again increased up to $180^{\circ} \mathrm{C}$ at a rate of $4^{\circ} \mathrm{C} / \mathrm{min}$. 


\section{Authentic standards and chemicals}

A standard for FAME (fatty acid methyl ester) was obtained from Supelco (Bellefonte, PA, USA). Chemicals such as 2,2-dimethoxypropane was purchased from Sigma-Aldrich (St. Louis, MO, USA). Benzene, n-heptanes, and sulfuric acid were acquired from Daejung Chemical Co., Ltd. (Gwangju Si, Gyeonggi-Do, Republic of Korea).

\section{Statistical analysis}

Means of two independent sample replications were used for all the statistical analyses. The significance of differences among cultivars (C), growing seasons $(\mathrm{S})$, plant parts $(\mathrm{P})$ and their interactions $(\mathrm{C} \times \mathrm{S}, \mathrm{C}$ $\times \mathrm{P}, \mathrm{S} \times \mathrm{P}$ and $\mathrm{C} \times \mathrm{S} \times \mathrm{P}$ ) was assessed by mixed model ANOVA by using SPSS (ver. 18; SPSS, Inc.,
Chicago, IL, USA). Relationships among fatty acids were assessed by multivariate analyses using Spearman's rank order correlation coefficients $(\mathrm{R})$ at $\mathrm{P} \leq 0.05$.

\section{Results and discussions}

\section{Fatty acid composition}

Descriptive analysis of fatty acid composition among different parts of broccoli cultivars in two growing seasons is presented in Table 1-3. Among the 37 fatty acids analyzed, only 14 fatty acids could be detected under our experimental conditions in both the seasons in floret part (Table 1). In spring season, most abundant fatty acid was palmitic acid (30.307 42.882\%), which was followed by linolenic (25.883 $33.843 \%)$ and linoleic acid (13.634 20.314\%), however linolenic acid showed highest compositional ratio

Table 1. Descriptive analysis of fatty acid composition in two seasons of broccoli cultivars in floret.

\begin{tabular}{|c|c|c|c|c|c|c|}
\hline \multirow{2}{*}{ Fatty acids (\%) } & \multicolumn{3}{|c|}{ Spring } & \multicolumn{3}{|c|}{ Fall } \\
\hline & Range & Mean & $\mathrm{CV}^{1)}(\%)$ & Range & Mean & CV (\%) \\
\hline Caproic (C6:0) & $0.073 \sim 0.169$ & 0.115 & 29.498 & $0.042 \sim 0.119$ & 0.071 & 44.465 \\
\hline Lauric (C12:0) & $0.103 \sim 0.317$ & 0.185 & 40.733 & $0.078 \sim 0.240$ & 0.125 & 34.835 \\
\hline Myristic (C14:0) & $0.612 \sim 1.181$ & 0.925 & 20.377 & $0.338 \sim 0.695$ & 0.468 & 22.993 \\
\hline Pentadecanoic (C15:0) & $0.342 \sim 0.542$ & 0.399 & 12.801 & $0.249 \sim 0.400$ & 0.306 & 16.726 \\
\hline Palmitic (C16:0) & $30.307 \sim 42.882$ & 34.297 & 9.709 & $26.685 \sim 40.548$ & 32.071 & 12.723 \\
\hline Palmitoleic (C16:1) & $0.478 \sim 0.766$ & 0.584 & 13.779 & $0.221 \sim 0.450$ & 0.331 & 20.980 \\
\hline Heptadecanoic (C17:0) & $0.369 \sim 0.611$ & 0.498 & 16.324 & $0.245 \sim 0.419$ & 0.314 & 17.985 \\
\hline Stearic (C18:0) & $7.381 \sim 13.058$ & 10.444 & 16.888 & $3.250 \sim 7.023$ & 5.034 & 21.698 \\
\hline Oleic $(\mathrm{C} 18: \ln 9 \mathrm{c})$ & $2.641 \sim 5.811$ & 4.139 & 24.678 & $0.734 \sim 3.251$ & 2.167 & 29.804 \\
\hline Linoleic (C18:2n6c) & $13.634 \sim 20.314$ & 16.578 & 10.729 & $13.672 \sim 19.025$ & 16.264 & 9.318 \\
\hline Linolenic (C18:3n3) & $25.883 \sim 33.843$ & 29.914 & 9.422 & $32.634 \sim 46.988$ & 41.254 & 11.641 \\
\hline Arachidic (C20:0) & $0.835 \sim 1.082$ & 0.974 & 7.985 & $0.440 \sim 0.864$ & 0.665 & 20.675 \\
\hline Behenic (C22:0) & $0.231 \sim 0.327$ & 0.289 & 10.108 & $0.178 \sim 0.331$ & 0.235 & 20.084 \\
\hline Lignoceric (C24:0) & $0.446 \sim 0.911$ & 0.659 & 19.726 & $0.554 \sim 0.973$ & 0.724 & 15.613 \\
\hline $\mathrm{SFA}^{2)}$ & $44.514 \sim 54.832$ & 48.786 & 6.263 & $32.918 \sim 49.814$ & 39.984 & 13.269 \\
\hline MUFA $^{3)}$ & $3.167 \sim 6.577$ & 4.722 & 22.199 & $1.069 \sim 3.670$ & 2.498 & 26.314 \\
\hline PUFA $^{4)}$ & $40.879 \sim 50.147$ & 46.491 & 6.087 & $46.908 \sim 66.013$ & 57.518 & 10.061 \\
\hline
\end{tabular}

${ }^{1)} \mathrm{CV}$ : Coefficient of variation.

${ }^{2)}$ SFA: Saturated fatty acid.

${ }^{3)}$ MUFA: Monounsaturated fatty acid.

${ }^{4)}$ PUFA: Polyunsaturated fatty acid. 
Jung-Ho Kwak / Seasonal variation in fatty acid composition in various parts of broccoli cultivars

Table 2. Descriptive analysis of fatty acid composition in two seasons of broccoli cultivars in leaf.

\begin{tabular}{|c|c|c|c|c|c|c|}
\hline \multirow{2}{*}{ Fatty acids (\%) } & \multicolumn{3}{|c|}{ Spring } & \multicolumn{3}{|c|}{ Fall } \\
\hline & Range & Mean & $\mathrm{CV}^{1)}(\%)$ & Range & Mean & CV (\%) \\
\hline Caproic (C6:0) & $\mathrm{N} / \mathrm{D}^{2)}$ & - & - & $\mathrm{N} / \mathrm{D}$ & - & - \\
\hline Lauric (C12:0) & $0.000 \sim 0.090$ & 0.058 & 41.515 & $0.000 \sim 0.052$ & 0.040 & 18.092 \\
\hline Myristic (C14:0) & $0.257 \sim 0.455$ & 0.359 & 16.490 & $0.161 \sim 0.277$ & 0.215 & 14.132 \\
\hline Pentadecanoic (C15:0) & $0.217 \sim 0.809$ & 0.469 & 35.046 & $0.227 \sim 0.605$ & 0.387 & 33.987 \\
\hline Palmitic (C16:0) & $23.668 \sim 31.236$ & 25.536 & 7.571 & $21.959 \sim 25.745$ & 22.922 & 4.739 \\
\hline Palmitoleic (C16:1) & $0.133 \sim 0.267$ & 0.211 & 16.843 & $0.087 \sim 0.177$ & 0.135 & 21.637 \\
\hline Heptadecanoic (C17:0) & $0.307 \sim 0.455$ & 0.350 & 11.935 & $0.193 \sim 0.297$ & 0.252 & 10.700 \\
\hline Stearic $(\mathrm{C} 18: 0)$ & $5.126 \sim 6.761$ & 5.721 & 10.077 & $3.095 \sim 4.068$ & 3.495 & 9.640 \\
\hline Oleic $(\mathrm{C} 18: \ln 9 \mathrm{c})$ & $2.502 \sim 4.363$ & 3.473 & 15.025 & $1.565 \sim 4.436$ & 2.633 & 30.733 \\
\hline Linoleic (C18:2n6c) & $12.569 \sim 14.784$ & 13.778 & 5.296 & $13.971 \sim 17.572$ & 16.408 & 6.187 \\
\hline Linolenic (C18:3n3) & $41.550 \sim 51.709$ & 48.811 & 5.362 & $49.121 \sim 54.584$ & 52.523 & 3.038 \\
\hline Arachidic (C20:0) & $0.423 \sim 0.683$ & 0.555 & 13.338 & $0.000 \sim 0.422$ & 0.301 & 34.466 \\
\hline Behenic (C22:0) & $0.170 \sim 0.277$ & 0.209 & 15.553 & $0.145 \sim 0.225$ & 0.182 & 16.192 \\
\hline Lignoceric (C24:0) & $0.387 \sim 0.707$ & 0.480 & 17.340 & $0.435 \sim 0.611$ & 0.518 & 9.599 \\
\hline $\mathrm{SFA}^{3)}$ & $31.597 \sim 40.911$ & 33.732 & 7.460 & $26.926 \sim 31.281$ & 28.301 & 4.497 \\
\hline MUFA $^{4)}$ & $2.700 \sim 4.616$ & 3.683 & 14.589 & $1.742 \sim 4.612$ & 2.768 & 29.450 \\
\hline PUFA $^{5)}$ & $54.787 \sim 65.083$ & 62.588 & 4.478 & $66.053 \sim 70.348$ & 68.931 & 1.850 \\
\hline
\end{tabular}

${ }^{1)} \mathrm{CV}$ : Coefficient of variation.

${ }^{2)} \mathrm{N} / \mathrm{D}$ : Not detected

${ }^{3)}$ SFA: Saturated fatty acid.

${ }^{4)}$ MUFA: Monounsaturated fatty acid.

${ }^{5)}$ PUFA: Polyunsaturated fatty acid.

(41.254\%) in fall season with the range of 32.634 46.988\%. In both of the seasons, all three major fatty acids exhibited quite similar cultivar dependent variation (9.318\% in linoleic acid to $12.723 \%$ in palmitic acid ) as measured by coefficient of variation (CV\%). The other fatty acids such as stearic and oleic acid also showed their considerable value in both of the seasons, however the values were higher in spring season compared to fall season. Other fatty acids; caproic, lauric, myristic, pentadecanoic, palmitoleic, arachidic, behenic and lignoceric acids were minor fatty acids and most of them showed less than $1 \%$ of total fatty acids in both of the seasons. Between the two seasons, total saturated fatty acid (SFA) and mono unsaturated fatty acid (MUFA) percentages were higher in spring season compared to fall season, while polyunsaturated fatty acid (PUFA) showed higher compositional ratio in fall season. Unlike the major fatty acids, SFA,
MUFA and PUFA showed higher cultivar dependent variation in fall season compared to spring season.

In leaves, all the fatty acids except lauric acid as present in floret parts were detected in both of the seasons (Table 2). The major fatty acids were similar as in floret parts; however most abundant fatty acid was linolenic (48.811\%) that was followed by palmitic (25.536\%) and linoleic acid (13.778\%) in spring season. Similar higher compositional ratio was found in fall season but palmitic acid exhibited higher ratio in spring season compared to fall season while both the linolenic and linoleic acids showed their higher compositional value in fall season than in spring season. Average SFA (33.732\%) and MUFA (3.683\%) in spring season were higher than in fall season, while PUFA showed their higher compositional ratio in fall season (68.931\%) than in spring season $(62.588 \%)$. Similar to the floret, leaf also exhibited 
Jung-Ho Kwak / Seasonal variation in fatty acid composition in various parts of broccoli cultivars

Table 3. Descriptive analysis of fatty acid composition in two seasons of broccoli cultivars in stem.

\begin{tabular}{|c|c|c|c|c|c|c|}
\hline \multirow{2}{*}{ Fatty acids (\%) } & \multicolumn{3}{|c|}{ Spring } & \multicolumn{3}{|c|}{ Fall } \\
\hline & Range & Mean & $\mathrm{CV}^{1)}(\%)$ & Range & Mean & CV (\%) \\
\hline Caproic (C6:0) & $\mathrm{N} / \mathrm{D}^{2)}$ & - & - & $0.108 \sim 0.231$ & 0.147 & 38.504 \\
\hline Lauric (C12:0) & $\mathrm{N} / \mathrm{D}$ & - & - & $0.153 \sim 0.276$ & 0.229 & 19.212 \\
\hline Myristic (C14:0) & $0.404 \sim 0.951$ & 0.616 & 27.284 & $0.057 \sim 0.550$ & 0.429 & 32.595 \\
\hline Pentadecanoic (C15:0) & $0.351 \sim 0.559$ & 0.444 & 13.939 & $0.262 \sim 0.480$ & 0.361 & 20.033 \\
\hline Palmitic (C16:0) & $34.550 \sim 52.268$ & 37.877 & 7.210 & $28.480 \sim 48.117$ & 41.574 & 13.995 \\
\hline Palmitoleic (C16:1) & $0.342 \sim 0.851$ & 0.719 & 19.152 & $0.315 \sim 0.523$ & 0.462 & 13.696 \\
\hline Heptadecanoic (C17:0) & $0.000 \sim 0.711$ & 0.520 & 37.515 & $0.232 \sim 0.474$ & 0.395 & 21.350 \\
\hline Stearic (C18:0) & $5.858 \sim 13.699$ & 8.816 & 28.012 & $2.284 \sim 7.671$ & 5.996 & 26.779 \\
\hline Oleic $(\mathrm{C} 18: \ln 9 \mathrm{c})$ & $2.936 \sim 8.151$ & 5.008 & 26.167 & $2.784 \sim 6.603$ & 5.041 & 22.530 \\
\hline Linoleic (C18:2n6c) & $10.781 \sim 17.458$ & 14.268 & 13.790 & $11.571 \sim 18.612$ & 14.720 & 17.326 \\
\hline Linolenic (C18:3n3) & $24.536 \sim 33.111$ & 29.881 & 8.268 & $21.086 \sim 43.773$ & 29.060 & 21.254 \\
\hline Arachidic (C20:0) & $0.000 \sim 1.011$ & 0.770 & 34.069 & $0.456 \sim 0.836$ & 0.676 & 17.260 \\
\hline Behenic (C22:0) & $0.241 \sim 0.392$ & 0.305 & 13.520 & $0.229 \sim 0.421$ & 0.316 & 18.913 \\
\hline Lignoceric (C24:0) & $0.577 \sim 0.852$ & 0.746 & 14.156 & $0.568 \sim 0.973$ & 0.806 & 17.300 \\
\hline $\mathrm{SFA}^{3)}$ & $44.386 \sim 55.628$ & 49.681 & 6.974 & $32.583 \sim 58.009$ & 50.717 & 15.099 \\
\hline MUFA $^{4)}$ & $3.278 \sim 8.879$ & 5.726 & 23.840 & $3.289 \sim 7.126$ & 5.503 & 20.608 \\
\hline PUFA $^{5)}$ & $38.166 \sim 49.349$ & 44.149 & 7.597 & $35.480 \sim 62.385$ & 43.780 & 17.882 \\
\hline
\end{tabular}

${ }^{1)} \mathrm{CV}$ : Coefficient of variation.

${ }^{2)} \mathrm{N} / \mathrm{D}$ : Not detected

${ }^{3)}$ SFA: Saturated fatty acid.

${ }^{4)}$ MUFA: Monounsaturated fatty acid.

${ }^{5)}$ PUFA: Polyunsaturated fatty acid.

higher SFA and MUFA in spring season and lower PUFA in fall season, however seasonal variation was not prominent compared to genotypic variation. In the leaves, we found comparatively higher ratio of omega-3 fatty acid i.e. linolenic acid, which suggests that leaves contribute more health beneficial activity for human health because omega-3 PUFAs have hypcholesteremic effect and inhibit the atherosclerotic process and coronary thrombosis (Connor and Connor, 1997).

In the case of stem, all the 14 fatty acids as present in floret parts are found in fall season; however two fatty acids; caproic and lauric acid were not detected in spring season (Table 3). Palmitic acid was the most abundant fatty acid (37.877\% in spring and $41.574 \%$ in fall season), which followed by linolenic and linoleic acid in both of the seasons. Variation due to the influence of cultivars was higher in fall season compared to spring season in major fatty acids as well as most of the minor fatty acids, which suggest that environmental factors are also responsible for the variation in fatty acids in broccoli stem. Although, average compositional ratio of major fatty acids was similar in both of the seasons, they showed more cultivar dependent variation in both of the seasons compared to floret and leaves. Average content of total SFA, MUFA and PUFA were 49.681\%, 5.726\% and $44.149 \%$, respectively in spring season. The value observed in fall season was also quite similar to the spring season; however cultivar dependent variation was higher in fall season than in spring season.

Among the three parts, stem exhibited comparatively higher SFAs in both the spring (49.681\%) and fall seasons $(50.717 \%)$ and highest compositional ratio of PUFAs were observed in leaves in both spring (62.588\%) and fall season (68.931\%). In contrast, floret part exhibited highest SFA and PUFA in spring and fall 
Table 4. Statistical analysis of variance for the fatty acid composition in broccoli cultivars.

\begin{tabular}{|c|c|c|c|c|c|c|c|c|c|c|c|c|c|c|c|c|c|}
\hline $\begin{array}{l}\text { Source of } \\
\text { variance }\end{array}$ & C6:0 & C12:0 & C14:0 & C15:0 & C16:0 & C16:1 & C17:0 & $\mathrm{C} 18: 0$ & $\begin{array}{c}\text { C18:1 } \\
\text { n9c }\end{array}$ & $\begin{array}{c}\mathrm{C} 18: 2 \\
\text { n9c }\end{array}$ & $\begin{array}{c}\text { C18:3 } \\
\text { n3 }\end{array}$ & C20:0 & $\mathrm{C} 22: 0$ & $\mathrm{C} 24: 0$ & $\mathrm{SFA}^{1)}$ & $\mathrm{MUFA}^{2)}$ & $\mathrm{PUFA}^{3)}$ \\
\hline Cultivars (C) & $* * *$ & $* * *$ & $* * *$ & $* * *$ & $* * *$ & $* * *$ & $* * *$ & $* * *$ & $* * *$ & $* * *$ & $* * *$ & $* * *$ & $* * *$ & $* * *$ & $* * *$ & $* * *$ & $* * *$ \\
\hline Seasons (S) & $* * *$ & $* * *$ & $* * *$ & $* * *$ & $* * *$ & $* * *$ & $* * *$ & $* * *$ & $* * *$ & $* * *$ & $* * *$ & $* * *$ & $* * *$ & $* * *$ & $* * *$ & $* * *$ & $* * *$ \\
\hline Parts (P) & $* * *$ & $* * *$ & $* * *$ & $* * *$ & $* * *$ & $* * *$ & $* * *$ & $* * *$ & $* * *$ & $* * *$ & $* * *$ & $* * *$ & $* * *$ & $* * *$ & $* * *$ & $* * *$ & $* * *$ \\
\hline $\mathrm{C} \times \mathrm{S}$ & $* * *$ & $* * *$ & $* * *$ & $* * *$ & $* * *$ & $* * *$ & $* * *$ & $* * *$ & $* * *$ & $* * *$ & $* * *$ & $* * *$ & $* * *$ & $* * *$ & $* * *$ & $* * *$ & $* * *$ \\
\hline $\mathrm{C} \times \mathrm{P}$ & $* * *$ & $* * *$ & $* * *$ & $* * *$ & $* * *$ & $* * *$ & $* * *$ & $* * *$ & $* * *$ & $* * *$ & $* * *$ & $* * *$ & $* * *$ & $* * *$ & $* * *$ & $* * *$ & $* * *$ \\
\hline $\mathrm{S} \times \mathrm{P}$ & - & $* * *$ & $* * *$ & $* *$ & $* * *$ & $* * *$ & $* * *$ & $* * *$ & $* * *$ & $* * *$ & $* * *$ & $* * *$ & $* * *$ & $* *$ & $* * *$ & $* * *$ & $* * *$ \\
\hline $\mathrm{C} \times \mathrm{S} \times \mathrm{P}$ & - & $* * *$ & $* * *$ & $* * *$ & $* * *$ & $* * *$ & $* * *$ & $* * *$ & $* * *$ & $* * *$ & $* * *$ & $* * *$ & $* * *$ & $* * *$ & $* * *$ & $* * *$ & $* * *$ \\
\hline
\end{tabular}

$* *, * * *$ Significant at $\mathrm{P}<0.01$ and 0.001 , respectively.

${ }^{1)}$ SFA: Saturated fatty acid; ${ }^{2)}$ MUFA: Monounsaturated fatty acid; ${ }^{3)}$ PUFA: Polyunsaturated fatty acid.

seasons, respectively. The presence of higher compositional ratio of PUFA in leaves suggests their higher health beneficial effects, as PUFA may decrease blood cholesterol levels (Hargrove et al., 2001) and improve HDL fluidity (Villa et al., 2002). Furthermore, leaves also exhibited lowest cultivar dependent variation (below 10\%) in major fatty acids; palmitic, linoleic and linolenic acid in both of the seasons. However, all the above results revealed that all the fatty acids were significantly affected by cultivars (C), plant parts (P) and growing seasons (S) (Table 4). Similarly, all the interactions $(C \times S, C \times P, S$ $\times \mathrm{P}$ and $\mathrm{C} \times \mathrm{S} \times \mathrm{P}$ ) were also significant. Similar cultivar dependent as well as seasonal dependent significant variation was also observed by Balouchi et al. (2011), Koh et al. (2009), Kurilich et al. (1999), Rosa and Rodrigues (2001), Rosa et al. (2001), Singh et al. (2007) and Vallejo et al. (2003) in various phytochemicals such as glucosinolates, vitamin C, phenolics, flavonoids, free sugars, however this is the first report that describes such variations (genotypic, seasonal as well as parts) in term of fatty acid composition in broccoli.

As we know that some saturated fatty acids such as lauric (12:0), myristic (14.0) and palmitic (16:0) acids (Denkeand Grundy, 1992; Zock et al., 1994) raise cholesterol levels, which is a major risk factor in $\mathrm{CHD}$ (Grundy, 1997), high compositional ratio of these fatty acids in food is not suitable for health. So, to overcome from this situation, development of cultivar having lower ratio of saturated fatty acid (higher UFA ratio), will be good for the human diet.

\section{Correlationship among fatty acids}

To understand the distribution pattern of various fatty acids in broccoli, we evaluated the correlation ship among fatty acids regardless of genotypes, their parts and growing seasons. The most abundant fatty acid; linolenic acid showed either significantly negative or no correlation ship with other fatty acids in that most significant negative correlation ship was observed with palmitic acid $\left(\mathrm{r}=-0.933^{* *}\right)$ which was followed by oleic acid ( $\mathrm{r}=-0.845 *$ ) (Table 5). Similar to the linolenic acid, linoleic acid also showed either negative or no correlationship with other fatty acids, however the relationship was poor ( $\mathrm{r}$ value below $-0.431^{* *}$ ) compared to that of linolenic acid. In contrast, palmitic acid, most abundant SFA showed significantly positive correlations with lignoceric acid $\left(\mathrm{r}=0.828^{* *}\right)$, behenic acid $\left(\mathrm{r}=0.821^{* *}\right)$, lauric acid $(\mathrm{r}=0.752 * *)$ and other fatty acids except with both PUFAs; linolenic and linoleic acid. These results indicate that decrease in compositional ratio in palmitic acid increases the compositional ratio of linolenic and linoleic acid. This is important because a breeding approach could focus on increasing the compositional ratio of unsaturated fatty acids such as 
Table 5. Correlation coefficients among fatty acids in broccoli.

\begin{tabular}{|c|c|c|c|c|c|c|c|c|c|c|c|c|c|}
\hline Fatty acids & $\mathrm{C} 12: 0$ & $\mathrm{C} 14: 0$ & C15:0 & C16:0 & $\mathrm{C} 16: 1$ & $\mathrm{C} 17: 0$ & C18:0 & $\mathrm{C} 18 \mathrm{~s} \ln 9 \mathrm{c}$ & $\mathrm{C} 18 \mathrm{2n} 9 \mathrm{c}$ & $\mathrm{C} 18: 3 \mathrm{n} 3$ & C20:0 & $\mathrm{C} 22: 0$ & $\mathrm{C} 24: 0$ \\
\hline C6:0 & 0.178 & 0.094 & $0.453 * *$ & $0.545^{* *}$ & 0.239 & $0.296^{*}$ & 0.208 & $0.396^{* *}$ & $-0.410 * *$ & $-0.628 * *$ & $0.372 * *$ & $0.390 * *$ & $0.306^{*}$ \\
\hline C12:0 & & $0.494 * *$ & -0.06 & $0.752 * *$ & $0.674 * *$ & $0.578^{* *}$ & $0.524 * *$ & $0.433^{* *}$ & -0.028 & $-0.787 * *$ & $0.632 * *$ & $0.702 * *$ & $0.675 * *$ \\
\hline C14:0 & & & 0.069 & $0.441^{* *}$ & $0.732 * *$ & $0.731 * *$ & $0.912 * *$ & $0.376^{* *}$ & -0.078 & $-0.675^{* *}$ & $0.695^{* *}$ & $0.516^{* *}$ & 0.272 \\
\hline C15:0 & & & & 0.02 & 0.110 & $0.318^{* *}$ & $0.193 *$ & 0.090 & $-0.431 * *$ & -0.016 & $0.165^{*}$ & 0.160 & -0.023 \\
\hline C16:0 & & & & & $0.712 * *$ & $0.567^{* *}$ & $0.471 * *$ & $0.523 * *$ & $-0.309 * *$ & $-0.933 * *$ & $0.643^{* *}$ & $0.821 * *$ & $0.828 * *$ \\
\hline C16:1 & & & & & & $0.737^{* *}$ & $0.765^{* *}$ & $0.609^{* *}$ & $-0.187^{*}$ & $-0.845^{* *}$ & $0.693 * *$ & $0.719^{* *}$ & $0.522 * *$ \\
\hline $\mathrm{C} 17: 0$ & & & & & & & $0.822 * *$ & $0.447 * *$ & $-0.424 * *$ & $-0.682 * *$ & $0.577^{* *}$ & $0.616^{* *}$ & $0.387 * *$ \\
\hline C18:0 & & & & & & & & $0.515^{* *}$ & $-0.273 * *$ & $-0.700^{*}$ & $0.632 * *$ & $0.511 * *$ & $0.271 *$ \\
\hline $\mathrm{C} 18: \ln 9 \mathrm{c}$ & & & & & & & & & $-0.266^{* *}$ & $-0.645^{* *}$ & $0.374^{* *}$ & $0.472 * *$ & $0.288^{* *}$ \\
\hline $\mathrm{C} 18 \mathrm{2} 2 \mathrm{n} 9 \mathrm{c}$ & & & & & & & & & & 0.163 & -0.147 & $-0.277 * *$ & $-0.224 *$ \\
\hline $\mathrm{C} 18: 3 \mathrm{n} 3$ & & & & & & & & & & & $-0.739 * *$ & $0.667 * *$ & $0.523 * *$ \\
\hline $\mathrm{C} 20: 0$ & & & & & & & & & & & & $-0.816^{* *}$ & $-0.729 * *$ \\
\hline $\mathrm{C} 22: 0$ & & & & & & & & & & & & & $0.756^{* *}$ \\
\hline
\end{tabular}

$*, * *$, Correlation is significant at $\mathrm{P}<0.05$ and 0.01 , respectively.

linoleic and linolenic acids, as these fatty acids are important for human health (Connor and Connor, 1997; Hargrove et al., 2001; Yaqoob, 2002). Fatty acids such as stearic and oleic acid showed significant correlations with most of the other fatty acids in that these fatty acids were negatively correlated with linoleic and linolenic acids and positively correlated with most of the other fatty acids. Among the 14 fatty acids, arachidic acid showed highest positive correlation with stearic acid $(r=0.912 *)$, while palmitic acid showed highest negative correlation with linolenic acid $(r=-0.933 * *)$.

\section{Conclusion}

This study summarizes about the fatty acid composition in various parts of broccoli cultivars in different seasons in that major fatty acids were palmitic, linoleic and linolenic acids comprising higher compositional ratio, however no special cultivar was noticed having higher compositional ratio of these fatty acids in all plant parts and growing seasons. Presence of higher compositional ratio of unsaturated fatty acids in broccoli signifies its nutritional value as these fatty acids are responsible for the promotion of human health by different ways.
Among three parts, leaf exhibited highest ratio of unsaturated fatty acids which indicates that leaves are also good for human health. Our results suggest that like other phytochemicals, fatty acids are also significantly influenced by the genotype of the cultivars (C), growing seasons (S) and plant parts (P) with higher variations in fall season compared to spring season. The major fatty acids showed least variations in leaves compared to floret and stem. Highest positive and negative correlation ship were found between myristic and stearic acid, and palmitic and linolenic acid among all the analyzed fatty acids, respectively.

\section{Acknowledgement}

This study was carried out with the support of "Cooperative Research Program for Agriculture Science \& Technology Development (Project No. PJ006722)” and "2013 Post Doctoral Course Program of National Institute of Horticultural \& Herbal Science”, Rural Development Administration, Republic of Korea.

\section{References}

Aronson WJ, Glaspy JA, Reddy ST, Reese D, Heber D, Bagga 
D. 2001. Modulation of omega-3/omega-6 polyunsaturated ratios with dietary fish oils in men with prostate cancer. Urology 58(2):283-288.

Barthet VJ. 2008. (n-7) and (n-9) cis-monounsaturated fatty acid contents of 12 Brassica species. Phytochemistry 69(2): 411-417.

Bhandari SR, Basnet S, Chung KH, Ryu KH, Lee YS. 2012. Comparisons of nutritional and phytochemical property of genetically modified CMV-resistant red pepper and its parental cultivar. Horticulture Environment and Biotechnology 53:151-157.

Balouchi Z, Peyvast GA, Ghasemnezhad M, Saadatian M. 2011. Changes of antioxidant compounds of broccoli (Brassica oleracea L. var. Italica) during storage at low and high temperatures. South Western Journal of Horticulture, Biology and Environment 2(2):193-212.

Connor SL, Connor WE. 1997. Are fish oils beneficial in the prevention and treatment of coronary artery disease? The American Journal of Clinical Nutrition 66(4):1020S-1031S.

Denke MA. Grundy SM. 1992. Comparison of effects of lauric acid and palmitic acid on plasma lipids and lipoproteins. The American Journal of Clinical Nutrition 56(5):895-898.

Grundy SM. 1997. What is the desirable ratio of saturated, polyunsaturated, and monounsaturated fatty acids in the diet? The American Journal of Clinical Nutrition 66(4): 988S-990S.

Hargrove RL, Etherton TD, Pearson TA, Harrison EH, KrisEtherton PM. 2001. Low fat and high monounsaturated fat diets decrease human low density lipoprotein oxidative susceptibility in vitro. Journal of Nutrition 131:1758-1763.

Iso $\mathrm{H}$, Sato $\mathrm{S}$, Umemura U, Kudo M, Koike K, Kitamura A, Imano H, Okamura T, Naito Y, Shimamoto T. 2002. Linoleic acid, other fatty acids and the risk of stroke. Stroke 33: 2086-2093.

Koh E, Wimalasiri KMS, Chassy AW, Mitchell AE. 2009. Content of ascorbic acid, quercetin, kaempferol and total phenolics in commercial broccoli. Journal of Food Composition and Analysis 22(7-8):637-643.

Kurilich AC, Tsau GJ, Brown A, Howard L, Klein BP, Jeffery EH, Kushad M, Wallig MA, Juvik JA. 1999. Carotene, tocopherol, and ascorbate contents in subspecies of Brassica oleracea. Journal of Agricultural and Food Chemistry 47(4):1576-1581.

Matthaus B, Vosmann K, Pham LQ, Aitzetmuller K. 2003. FA and tocopherol composition of Vietnamese oil seeds. Journal of the American Oil Chemists' Society 80(10):1013-1020.

Podsedek A. 2007. Natural antioxidants and antioxidant capacity of Brassica vegetables: a review. LWT- Food Science and Technology 40(1):1-11.

Rosa EAS, Rodrigues AS. 2001. Total and individual glucosinolate content in 11 broccoli cultivars grown in early and late seasons. HortScience 36(1):56-59.

Rosa E, David M, Gomes MH. 2001. Glucose, fructose and sucrose content in broccoli, white cabbage and Portuguese cabbage grown in early and late seasons. Journal of the Science of Food and Agriculture 81:1145-1149.

Simopoulos AP. 2002. The importance of the ratio of omega-6/ omega-3 essential fatty acids. Biomedicine and Pharmacotherapy 56:365-379.

Singh J, Upadhyay AK, Prasad K, Bahadur A, Rai M. 2007. Variability of carotenes, vitamin $\mathrm{C}, \mathrm{E}$ and phenolics in Brassica vegetables. Journal of Food Composition and Analysis 20(2):106-112.

Vallejo F, Tomas-Barberan FA, Garcia-Viguera C. 2003. Effect of climatic and sulphur fertilization conditions, on phenolic compounds and vitamin $\mathrm{C}$, in the inflorescences of eight broccoli cultivars. European Food Research and Technology 216(5):395-401.

Velasco L, Goffman FD, Becker HC. 1998. Variability for the fatty acid composition of the seed oil in a germplasm collection of the genus Brassica. Genetic Resources and Crop Evolution 45(4):371-382.

Vidrih R, Filip S, Hribar J. 2009. Content of higher fatty acids in green vegetables. Czech Journal of Food Science 27: S125-S129.

Villa B, Calabresi L, Chiesa G, Rise P, Galli C, Sirtori CR. 2002. Omega-3 fatty acid ethyl esters increase heart rate variability in patients with coronary disease. Pharmacological Research 45(6):475-478.

West L, Tsui I, Balch B, Meyer K, Huth PJ. 2003. Determination of health implication of the erucic acid content of broccoli florets, sprouts, and seeds. Journal of Food Science 67(7): 2641-2643.

Yaqoob P. 2002. Monounsaturated fatty acids and immune function. European Journal of Clinical Nutrition 56(Suppl 3):S9-S13.

Zock PL, de Vries JH, Katan MB. 1994. Impact of myristic acid versus palmitic acid on serum lipid and lipoprotein levels in healthy women and men. Arteriosclerosis, Thrombosis and Vascular Biology 14(4):567-575. 